\title{
Perfil pragmático longitudinal de uma criança no espectro da neuropatia auditiva
}

\author{
Longitudinal pragmatic profile of a child with auditory \\ neuropathy spectrum disorder
}

\author{
Andreza Carolina Bretanha', Karina Ferreira', Regina Tangerino de Souza Jacob ${ }^{2}$, \\ Adriane Lima Mortari Moret ${ }^{2}$, Simone Aparecida Lopes-Herrera ${ }^{2}$
}

\begin{abstract}
RESUMO
A maior parte da comunicação humana depende da conversão de ideias em linguagem, envolvendo a interação de todos os seus componentes - fonológico, semântico, sintático e pragmático. A pragmática estuda a relação entre o significado social da linguagem e seu conteúdo semântico, manifestado pelo ato comunicativo em si. O espectro da neuropatia auditiva gera uma dessincronia na condução nervosa, contribuindo para o prejuízo na percepção da fala. Na criança deficiente auditiva, o processo de aquisição e desenvolvimento da linguagem pode ser estimulado com a intervenção. O objetivo dessa pesquisa foi realizar acompanhamento longitudinal do uso das habilidades pragmáticas de comunicação por uma criança com espectro da neuropatia auditiva. A criança realizou intervenção fonoaudiológica por três anos na área de Audiologia Educacional. Foram gravadas conversações espontâneas, ao início de cada ano, transcritas e analisadas segundo protocolo de habilidades comunicativas verbais. Na gravação inicial, a criança apresentou maior número de habilidade de respostas diretas; porém, estas foram ampliadas com o fornecimento de respostas mais complexas ao longo da intervenção. Na última gravação, já propõe novos tópicos de discurso, realiza narrativas e argumentações. O surgimento de habilidades comunicativas refinadas é explicado pelo desenvolvimento da linguagem, que é potencializado pela terapia com deficientes auditivos. Pode-se concluir que para o caso apresentado a intervenção fonoaudiológica proporcionou melhora nas habilidades pragmáticas de comunicação.
\end{abstract}

Descritores: Neuropatia auditiva; Linguagem; Perda auditiva; Comunicação; Reabilitação dos transtornos da fala e da linguagem; Reabilitação de deficientes auditivos; Criança

\section{INTRODUÇÃO}

Embora os seres humanos também se comuniquem através da linguagem não-verbal, a maior parte da comunicação humana depende da conversão de ideias em linguagem, escrita e oral.

A linguagem oral é um complexo processo que envolve a participação e a interação de todos os seus componentes - fonológico, semântico, sintático e pragmático ${ }^{(1)}$ - inclusos, neste último, os aspectos funcionais da comunicação e do uso efetivo

Trabalho realizado no Departamento de Fonoaudiologia da Faculdade de Odontologia de Bauru, Universidade de São Paulo, pelo Programa de PósGraduação (Mestrado) em Fonoaudiologia - USP - Bauru (SP), Brasil.

(1) Programa de Pós-Graduação (Mestrado) em Fonoaudiologia da Faculdade de Odontologia de Bauru, Universidade de São Paulo - USP - Bauru (SP), Brasil.

(2) Departamento de Fonoaudiologia da Faculdade de Odontologia de Bauru, Universidade de São Paulo - USP - Bauru (SP), Brasil.

Endereço para correspondência: Simone Aparecida Lopes-Herrera. Al. Octávio Pinheiro Brisola, 9/75, Vl. Nova Cidade Universitária, Bauru (SP), Brasil, CEP: 17012-901.E-mail: lopesimone@usp.br Recebido em: 16/3/2010; Aceito em: 16/2/2011 da linguagem. A aquisição e organização desses componentes estão relacionadas a capacidades internas do ser humano e também ao seu ambiente. Qualquer comprometimento em um ou mais desses componentes trará consequências para o desenvolvimento da linguagem de maneira geral ${ }^{(1)}$.

A pragmática é entendida como a área da Linguística que estuda a relação entre o significado social da linguagem - expresso pelo conteúdo interacional - e seu conteúdo semântico - manifestado pelo ato comunicativo em $\mathrm{si}^{(2)}$.

Para que a comunicação aconteça de maneira eficaz, é necessária a integridade de algumas estruturas e sistemas, entre elas o sistema auditivo ${ }^{(3)}$, pois a criança depende do contato com o mundo exterior, por meio dos seus sentidos, para experimentar situações que influenciarão seu desenvolvimento psico-social.

Os três primeiros anos de vida de uma criança são críticos para a aquisição de informações sobre o mundo. A partir da interação e da comunicação com a família, e do estabelecimento de uma base cognitiva e linguística, o desenvolvimento global da criança se desdobra ${ }^{(4)}$. Soma-se a isto o fato de que, se a criança for capaz de desenvolver habilidades de lingua- 
gem oral apropriadas à idade, ingressará mais preparada na escola para participar plenamente nas interações sociais com os professores e colegas ${ }^{(4)}$.

A literatura é clara quanto à importância da audição para a aquisição e o desenvolvimento da linguagem oral ${ }^{(4,5)}$. Há na literatura um estudo que caracterizou o perfil pragmático de crianças deficiente auditivas; algumas utilizavam aparelhos de amplificação sonora individuais e outras faziam uso de implante coclear. Foi realizada comparação do perfil pragmático dessas crianças com outras, de mesma idade, sem alterações auditivas. As crianças com deficiência auditiva utilizaram variedades de funções pragmáticas, porém, quando comparadas às normais, demonstraram uso inapropriado de algumas funções. Não houve diferenças no perfil pragmático entre as crianças que utilizam aparelho de amplificação sonora individuais e implante coclear ${ }^{(3)}$.

O Espectro da Neuropatia Auditiva (ENA) é um diagnóstico clínico relativamente recente utilizado para descrever os indivíduos com distúrbios auditivos ${ }^{(5,6)}$, devidos à disfunção nas sinapses das células ciliadas internas e nervo auditivo e/ou no nervo auditivo em $\mathrm{si}^{(5)}$. As características clínicas do espectro incluem desde limiares auditivos tonais dentro da normalidade até perda auditiva bilateral de grau severo ou profundo ${ }^{(7,8)}$ ou variável, nos casos em que há acometimento do nervo auditivo, que gera uma dessincronia na condução nervosa. O ENA pode ser constatado em pacientes com idade variadas ${ }^{(7)}$.

$\mathrm{O}$ indivíduo com ENA apresenta o funcionamento das células ciliadas externas compatíveis com a normalidade, mas a função do nervo vestíbulo-coclear (VIII par craniano) alterada ${ }^{(9)}$. Entretanto, a literatura aponta que $30 \%$ das pessoas com ENA podem apresentar comprometimento das células ciliadas externas e consequente perda das emissões otoacústicas $^{(8)}$. Nestes casos, a ausência das emissões otoacústicas não exclui o diagnóstico do ENA. O registro do microfonismo coclear registrado nos potenciais evocados auditivos de tronco encefálico deve compor a bateria para o diagnóstico de $\mathrm{ENA}^{(8)}$.

A habilitação e a reabilitação auditiva nesses indivíduos são um desafio, pois a alteração da função neural leva ao comprometimento da percepção auditiva da fala, e os limiares tonais podem variar de normais até severamente prejudicados ${ }^{(5)}$.

$\mathrm{Na}$ criança com deficiência auditiva ou com ENA o processo de aquisição e desenvolvimento da linguagem pode ser prejudicado. Devido à dificuldade de recepção auditiva, ela poderá apresentar também prejuízos fonético-fonológicos, articulatórios e de ressonância ${ }^{(3)}$.

Pesquisas na área da Audiologia mostram que o desenvolvimento de habilidades pragmáticas nas crianças deficientes auditivas é mais lento do que em seus pares ouvintes ${ }^{(3,10)}$ ou seja, apresentam maior frequência de uso de habilidades menos complexas e de inadequações quando comparadas a seus pares. A intervenção fonoaudiológica é necessária para conduzir a criança no processo de desenvolvimento da linguagem, assim como para a orientação e o aconselhamento familiar.

Essa pesquisa teve como objetivo realizar o acompanhamento longitudinal do uso das habilidades pragmáticas de comunicação por uma criança com diagnóstico de espectro da neuropatia auditiva.

\section{APRESENTAÇÃO DO CASO CLÍNICO}

Todos os procedimentos dessa pesquisa foram submetidos e aprovados pelo Comitê de Ética e Pesquisa da Faculdade de Odontologia de Bauru da Universidade de São Paulo (FOBUSP) de origem, processo número 006/2010.

Segundo dados coletados em prontuário, J. R. D. N., gênero masculino, em fevereiro de 2006, com 3 anos e 9 meses, recebeu o diagnóstico de distúrbio do desenvolvimento da linguagem secundário a quadro de comprometimento auditivo - ENA, após avaliação médica otorrinolaringológica e avaliação fonoaudiológica.

$\mathrm{Na}$ anamnese, foram constatados relatos dos pais quanto à flutuação da audição. Na avaliação clínica fonoaudiológica foram constatadas alterações em todos os níveis de linguagem, inclusive o pragmático. $\mathrm{Na}$ audiometria tonal limiar condicionada realizada nas frequências de $500 \mathrm{~Hz}$ a $4 \mathrm{kHz}$, foi constatada perda auditiva sensorioneural de grau moderado bilateral. O limiar de reconhecimento de fala (SRT) foi de $60 \mathrm{~dB}$ na orelha direita e de $55 \mathrm{~dB}$ na orelha esquerda. $\mathrm{Na}$ imitanciometria constatou-se curva timpanométrica com complacência de 0 daPa bilateralmente e pressão de pico de $0,5 \mathrm{ml}$ na orelha direita e de $0,4 \mathrm{ml}$ na orelha esquerda, compatíveis com funcionalidade normal de orelha média bilateralmente, com ausência de reflexos acústicos bilaterais. Na pesquisa das Emissões Otoacústicas Evocadas Transientes observou-se ausência de resposta bilateralmente. Nos Potenciais Evocados Auditivos de Tronco Encefálico (PEATE) ausência de resposta neural e presença de microfonismo coclear, bilateralmente. O microfonismo foi evidenciado pelo bloqueio do tubo do fone de inserção $3 \mathrm{~A}$ durante o exame do PEATE, quando da exclusão da hipótese de presença de artefato elétrico. Concluiu-se que a criança apresentava distúrbio do desenvolvimento da linguagem secundário a quadro de ENA.

Iniciou-se o processo de intervenção fonoaudiológica em março de 2006, quando a criança tinha 3 anos e 10 meses, com terapia fonoaudiológica aurioral ${ }^{(11)}$.

Nessa modalidade terapêutica, as estratégias dão ênfase ao desenvolvimento das habilidades auditivas para favorecer a aquisição e o desenvolvimento da linguagem oral. Além disso, valoriza-se a orientação e o aconselhamento familiar constantes. Foram adaptados aparelhos de amplificação sonora digitais de ganho médio, de dois canais com compressão de área dinâmica ampla (WDRC - Wide Dynamic Range Compression) em ambas as orelhas, com ganho prescritivo pela regra DSL, a partir da predição de limiares em 50 dBNA. Atualmente faz uso de sistema de frequência modulada (FM) em ambas as orelhas, com ganho prescritivo pela regra prescritiva não-linear, National Acoustic Laboratories' Nonlinear (NAL NL1) com os limiares variando de 45 dBNA a 60 dBNA na orelha direita, e $35 \mathrm{dBNA}$ a $60 \mathrm{dBNA}$ na orelha esquerda, nas frequências de $250 \mathrm{~Hz}$ a $8 \mathrm{kHz}$.

A criança tem 7 anos e 6 meses e está realizando terapia fonoaudiológica aurioral há 3 anos e 9 meses, desde que recebeu o diagnóstico.

O material analisado foi coletado nos anos de 2007 a 2009. Foram gravadas em vídeo situações de interação espontânea 
entre criança e fonoaudiólogo, com duração de 30 minutos, com registros anuais. Foram analisadas três gravações de 90 minutos, a partir das quais levantou-se o perfil pragmático anual, correspondente a cada ano em que a criança permaneceu em intervenção terapêutica, conforme descrição abaixo:

- Gravação 1, realizada no ano de 2007, quando a criança estava com a idade de 5 anos, um ano após o inicio do processo de intervenção fonoaudiológica.

- Gravação 2, realizada no ano de 2008, quando a criança estava com a idade de 6 anos, dois anos após o inicio do processo de intervenção fonoaudiológica.

- Gravação 3, realizada no ano de 2009, quando a criança estava com a idade de 7 anos, três anos após o inicio do processo de intervenção fonoaudiológica.

Cada registro de interação espontânea entre criança e fonoaudiólogo foi transcrito e analisado segundo protocolo específico ${ }^{(12)}$. O referido protocolo continha três colunas, a primeira para identificar o interlocutor, a segunda para transcrever o turno dialógico, e a terceira para categorizar as Habilidades Comunicativas Verbais - HCV (Anexo 1), que constam de habilidades dialógicas, de regulação, narrativo-discursivas e não-interativas. Cada uma dessas categorias é dividida em subcategorias, num total de 24 possíveis categorizações das habilidades comunicativas verbais.

Foram observadas as HCV da criança, ao longo dos anos de 2007, 2008 e 2009. Ocorreu maior aumento das habilidades narrativo-discursivas (HND) com o passar dos anos; as habilidades dialógicas (HD) em 2007, na gravação 1, apresentaramse em número maior que os anos posteriores. Observou-se, ainda, a porcentagem de ocorrência das HCV da criança e do adulto. As HND no adulto também foram aumentando com o passar dos anos e a habilidade de regulação (HR) apresentouse com maior porcentagem em 2007, na gravação 1 (Figura 1, Tabela 1).

Em relação às HD, observa-se que a criança aumentou o número de inserções de novos tópicos (NT) no diálogo de 2007 (gravação 1) para 2008 (gravação 2), e apresentou maior número de organização dialógica sequencial (OS) em 2007, na gravação 1 (Figura 2).

Observa-se que o adulto foi o interlocutor que mais iniciou turnos nos períodos analisados e que a porcentagem de OS foi menor no adulto quando comparada com a criança. Em relação à criança, ocorreu maior porcentagem de OS em 2007 , na gravação 1, e maior porcentagem da habilidade de iniciar turnos em 2008, gravação 2 (Tabela 2).

Observa-se que em 2007, na gravação 1 , em relação às habilidades de OS, a criança apresentou número maior de respostas diretas (RD) em relação aos outros anos. Observase que a porcentagem de feedback ao interlocutor (FI) no adulto vai diminuindo com o passar dos anos (Figura 3, Tabela 3).

No que se refere às HR, ocorreu aumento no número de ocorrências da habilidade de solicitação de informação (SI) com o passar dos anos. Nota-se que a porcentagem de uso da habilidade de SI diminuiu no adulto no decorrer dos anos (Figura 4, Tabela 4).

Em relação às HND da criança, elas ocorreram somente a partir de 2008 (gravação 2); com aumento do número de ocorrências dessa habilidade em 2009 (gravação 3). Nota-se similaridade do perfil comunicativo em relação às HND da criança e do adulto, reiterando a qualidade das interações entre esses interlocutores (Figura 5, Tabela 5).

Tabela 1. Habilidades comunicativas verbais utilizadas pela criança e pelo adulto no período de 2007 a 2009

\begin{tabular}{|c|c|c|c|c|c|c|}
\hline \multirow{2}{*}{ Habilidades comunicativas verbais } & \multicolumn{3}{|c|}{ Criança } & \multicolumn{3}{|c|}{ Adulto } \\
\hline & 2007 & 2008 & 2009 & 2007 & 2008 & 2009 \\
\hline HD & 84,2 & 80,1 & 75,9 & 51,6 & 63 & 56,7 \\
\hline HR & 15,8 & 15,7 & 16,4 & 48,4 & 36,5 & 41,4 \\
\hline HND & 0 & 3,2 & 7,7 & 0 & 0,5 & 1,9 \\
\hline
\end{tabular}

Valores expressos em \%

Legenda: $\mathrm{HD}$ = habilidades dialógicas; $\mathrm{HR}$ = habilidades de regulação; $\mathrm{HND}=$ habilidades narrativo-discursivas

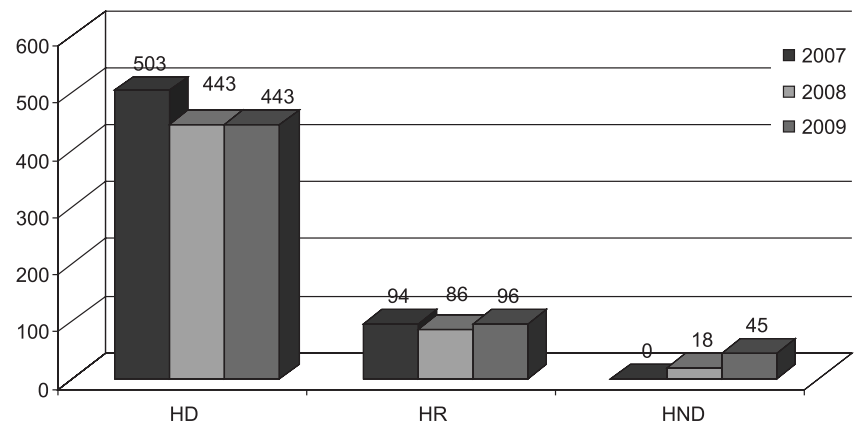

Legenda: $\mathrm{HD}$ = habilidades dialógicas; $\mathrm{HR}$ = habilidades de regulação; $\mathrm{HND}=$ habilidades narrativo-discursivas

Figura 1. Habilidades comunicativas verbais utilizadas pela criança no período de 2007 a 2009 (em número).

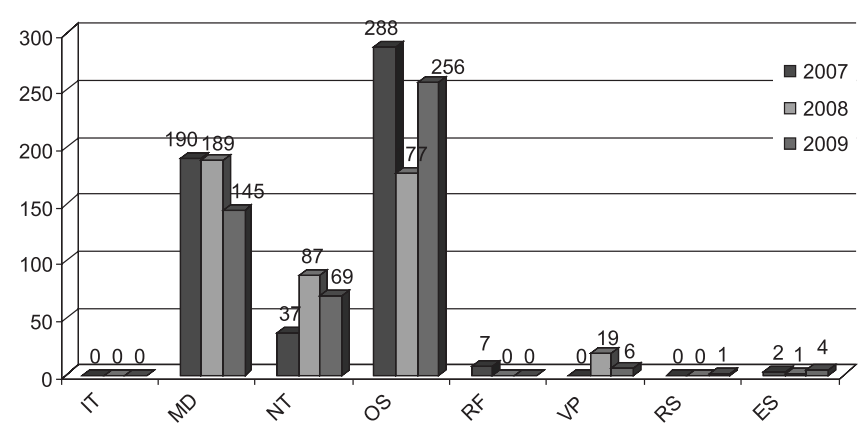

Legenda: IT = início de turno; MD = manutenção de diálogo; NT = inserção de novos tópicos no diálogo; OS = organização dialógica sequencial; RF = reparação de falhas; VP = variação de papeis; $\mathrm{RS}$ = rotina social; $\mathrm{ES}$ = expressão de sentimentos

Figura 2. Habilidades dialógicas utilizadas pela criança no período de 2007 a 2009 (em número). 
Tabela 2. Habilidades dialógicas utilizadas pela criança e pelo adulto no período de 2007 a 2009

\begin{tabular}{|c|c|c|c|c|c|c|}
\hline \multirow{2}{*}{ Habilidades dialógicas } & \multicolumn{3}{|c|}{ Criança } & \multicolumn{3}{|c|}{ Adulto } \\
\hline & 2007 & 2008 & 2009 & 2007 & 2008 & 2009 \\
\hline IT & 0,0 & 0,0 & 0,0 & 0,4 & 0,6 & 0,2 \\
\hline MD & 36,3 & 39,9 & 30,2 & 58,7 & 61,3 & 54,8 \\
\hline NT & 7,0 & 18,3 & 14,4 & 23,6 & 21,2 & 24,0 \\
\hline os & 55,0 & 37,4 & 53,2 & 17,3 & 11,4 & 18,5 \\
\hline $\mathrm{RF}$ & 1,3 & 0,0 & 0,0 & 0,0 & 0,0 & 0,0 \\
\hline VP & 0,0 & 4,1 & 1,2 & 0,0 & 5,1 & 0,7 \\
\hline RS & 0,0 & 0,0 & 0,2 & 0,0 & 0,0 & 0,7 \\
\hline ES & 0,4 & 0,3 & 0,8 & 0,0 & 0,4 & 1,1 \\
\hline
\end{tabular}

Valores expressos em \%

Legenda: IT = início de turno; $M D$ = manutenção de diálogo; NT = inserção de novos tópicos no diálogo; OS = organização dialógica sequencial; RF = reparação de falhas; $\mathrm{VP}$ = variação de papeis; $\mathrm{RS}$ = rotina social; $\mathrm{ES}$ = expressão de sentimentos

Tabela 3. Subcategorias da habilidade dialógica de organização sequencial utilizada pela criança e pelo adulto no período de 2007 a 2009

\begin{tabular}{|c|c|c|c|c|c|c|}
\hline \multirow{2}{*}{ Subcategorias } & \multicolumn{3}{|c|}{ Criança } & \multicolumn{3}{|c|}{ Adulto } \\
\hline & 2007 & 2008 & 2009 & 2007 & 2008 & 2009 \\
\hline $\mathrm{CM}$ & 26,1 & 38,0 & 31,6 & 72,1 & 47,5 & 55,3 \\
\hline $\mathrm{RD}$ & 63,8 & 61,5 & 59,6 & 22,2 & 47,5 & 42,7 \\
\hline I & 0,0 & 0,0 & 0,0 & 0 & 0 & 0 \\
\hline $\mathrm{FI}$ & 10,1 & 0,5 & 8,8 & 5,8 & 5,0 & 3,0 \\
\hline
\end{tabular}

Valores expressos em \%

Legenda: $\mathrm{CM}=$ comentários; $\mathrm{RD}$ = respostas diretas; I = imitação; FI = feedback ao interlocutor

Tabela 4. Habilidades de regulação utilizadas pela criança e pelo adulto no período de 2007 a 2009

\begin{tabular}{|c|c|c|c|c|c|c|}
\hline \multirow[t]{2}{*}{ Habilidades de regulação } & \multicolumn{3}{|c|}{ Criança } & \multicolumn{3}{|c|}{ Adulto } \\
\hline & 2007 & 2008 & 2009 & 2007 & 2008 & 2009 \\
\hline AR & 0,0 & 4,7 & 1,9 & 0,0 & 2,6 & 0,3 \\
\hline DAT & 42,8 & 19,8 & 26,5 & 4,7 & 6,3 & 7,5 \\
\hline DAO & 2,2 & 5,8 & 7,9 & 7,3 & 9,3 & 6,9 \\
\hline so & 1,1 & 0,0 & 0,0 & 0,2 & 0,0 & 0,0 \\
\hline SI & 53,9 & 69,7 & 62,8 & 86,8 & 81,9 & 85,0 \\
\hline CS & 0,0 & 0,0 & 0,9 & 0,9 & 0,0 & 0,3 \\
\hline
\end{tabular}

Valores expressos em \%

Legenda: $\mathrm{AR}$ = auto-regulatória; $\mathrm{DAT}=$ direcionamento de atenção; $\mathrm{DAO}=$ direcionamento de ação; $\mathrm{SO}$ = solicitação de objeto; $\mathrm{SI}=$ solicitação de informação; $\mathrm{CS}$ $=$ consentimento

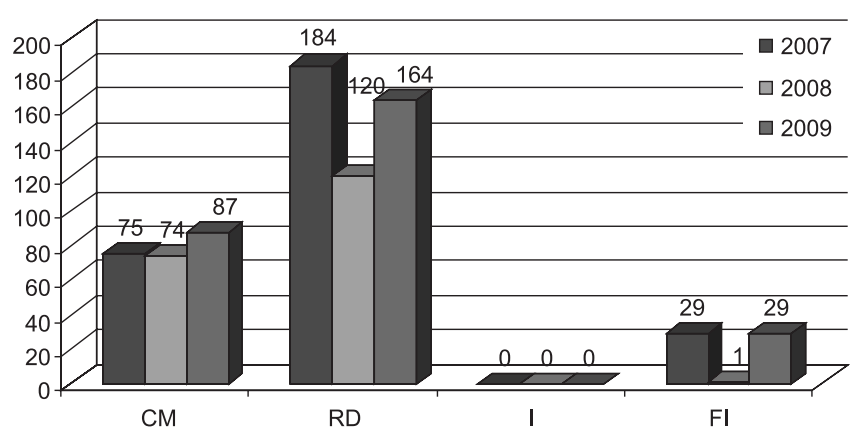

Legenda: $\mathrm{CM}=$ comentários; $\mathrm{RD}$ = respostas diretas; $\mathrm{I}=$ imitação; $\mathrm{FI}$ = feedback ao interlocutor

Figura 3. Subcategorias da habilidade dialógica de organização sequencial utilizadas pela criança no período de 2007 a 2009 (em número).

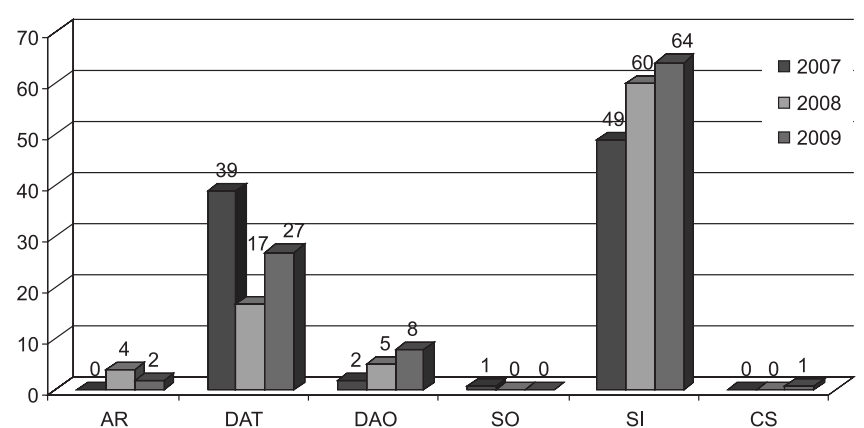

Legenda: $A R$ = auto-regulatória; $D A T$ = direcionamento de atenção; $D A O=$ direcionamento de ação; SO = solicitação de objeto; SI = solicitação de informação; CS = consentimento

Figura 4. Habilidades de regulação utilizadas pela criança no período de 2007 a 2009 (em número). 
Tabela 5. Habilidades narrativo-discursivas utilizadas pela criança e pelo adulto no período de 2007 a 2009

\begin{tabular}{lccccccc}
\hline \multirow{2}{*}{ Habilidades narrativo-discursivas } & \multicolumn{3}{c}{ Criança } & & \multicolumn{3}{c}{ Adulto } \\
\cline { 2 - 4 } \cline { 5 - 7 } & 2007 & 2008 & 2009 & & 2007 & 2008 & 2009 \\
\hline RH & 0,0 & 100,0 & 86,0 & 0 & 100,0 & 78,5 \\
RPH & 0,0 & 0,0 & 0,0 & & 0 & 0,0 & 0,0 \\
IH & 0,0 & 0,0 & 0,0 & & 0 & 0,0 & 0,0 \\
ARG & 0,0 & 0,0 & 14,0 & & 0 & 0,0 & 17,5 \\
\hline
\end{tabular}

Valores expressos em \%

Legenda: $\mathrm{AR}$ = auto-regulatória; DAT = direcionamento de atenção; DAO = direcionamento de ação; SO = solicitação de objeto; SI = solicitação de informação; $\mathrm{CS}=$ consentimento

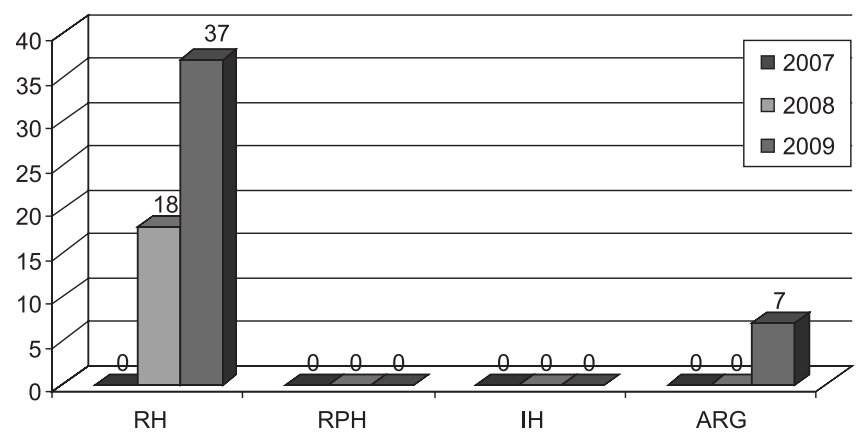

Legenda: $\mathrm{RH}$ = relato de histórias ou acontecimentos; $\mathrm{RPH}=$ reprodução de histórias; IH = interpretação de histórias; $A R G$ = argumentação

Figura 5. Habilidades narrativo-discursivas utilizadas pela criança no período de 2007 a 2009 (em número).

\section{DISCUSSÃO}

A audição é pré-requisito para a aquisição e o desenvolvimento da linguagem e essas duas funções são interdependentes. A deficiência auditiva na infância pode ocasionar atrasos de fala e linguagem, na medida em que interfere na recepção dos sons e monitoramento da própria fala (feedback acústico-articulatório $)^{(3)}$. No ENA a fala e o desenvolvimento da linguagem podem estar alterados. O desenvolvimento das habilidades auditivas funcionais, a identificação e o acompanhamento das alterações podem ser preditos, de modo abrangente, com base nos resultados dos testes auditivos e nas habilidades individuais, como habilidades auditivas flutuantes ${ }^{(5)}$.

Indivíduos diagnosticados com ENA têm se beneficiado de aparelhos de amplificação sonora individuais, com melhora nas habilidades de percepção de fala e desenvolvimento da linguagem. Esses resultados criam expectativas favoráveis para o desenvolvimento das crianças com ENA, que não deve ser diferente do observado numa criança deficiente auditiva típica, com perda auditiva neurossensorial ${ }^{(11)}$.

Crianças com acesso tardio à intervenção fonoaudiológica e uso de amplificação diferem das crianças com audição normal na qualidade e na extensão das suas experiências auditivas/linguísticas ${ }^{(10)}$, corroborando os dados do estudo aqui apresentado. A criança deste estudo apresentou refinadas habilidades narrativo-discursivas e de argumentação, conforme a intervenção fonoaudiológica foi avançando.

A aquisição da linguagem oral no ENA é possível, desde que asseguradas as condições de intervenção necessárias. Ressalta-se que a qualidade das interações entre a criança e seus cuidadores nesse processo de aquisição e desenvolvimento da linguagem é fator essencial.

A amplificação dos sons da fala com o uso de aparelhos de amplificação sonora individuais e a inserção de orientações terapêuticas para a família sobre a estimulação da linguagem oral nas rotinas domiciliares da criança podem incentivar o desenvolvimento da mesma, além das intervenções terapêuticas fonoaudiológicas.

Nota-se a importância da qualidade das interações entre os interlocutores, visto que no estudo aqui realizado ocorre similaridade no perfil pragmático do adulto e da criança. Ressalta-se que o adulto deve variar as habilidades comunicativas utilizadas, fazendo uso inclusive das mais complexas, expandindo o discurso e dando possibilidade para que a criança apreenda as novas estruturas.

A maior ocorrência de habilidades dialógicas no discurso da criança é justificada pela maior ocorrência de habilidades de regulação pelo adulto, necessárias para regular o comportamento comunicativo da criança. Como resposta, há troca de informações obedecendo regras sociais de estabelecimento de diálogos.

Entretanto, na progressão da intervenção fonoaudiológica, percebe-se mudanças nesse perfil da criança. Ela supera o comportamento restrito de responder às solicitações propostas pelo adulto, e passa a regular o comportamento do adulto no seu próprio discurso. Para isso, utiliza, por exemplo, a habilidade de solicitar informações.

Algumas habilidades comunicativas apresentaram variabilidade de uso, no decorrer dos anos. Por exemplo, a habilidade manutenção de diálogo diminuiu percentualmente de 2007 para 2008, e aumentou em 2009, ou a habilidade expressão de sentimentos diminuiu percentualmente de 2007 para 2008, aumentando em 2009. Isso é explicado pela variabilidade das situações analisadas, embora o ambiente de avaliação tenha sido controlado, com a tentativa de reproduzir as situações. Outra explicação para a variabilidade é que quando aumenta o uso de determinada habilidade, outras podem diminuir.

Os recursos da intervenção fonoaudiológica também possibilitam melhora da qualidade vocal e de ajustes fonatórios, favorecendo maior inteligibilidade da fala de indivíduos com deficiência auditiva ${ }^{(13)}$, o que pode ser evidenciado pela diminuição das solicitações do interlocutor. Em outras palavras, na medida em que a fala se torna mais inteligível, o adulto compreende melhor o que foi falado e não precisa pedir repetições.

Conforme progride a aquisição e o desenvolvimento da linguagem, há evolução do perfil pragmático de modo glo- 
bal, e o uso de habilidades mais elaboradas de comunicação, como a inserção de novos tópicos no diálogo, reprodução e elaboração de histórias e argumentação pode ser observado na conversação.

\section{COMENTÁRIOS FINAIS}

O surgimento de habilidades comunicativas mais com- plexas e elaboradas é expresso pela qualidade das interações entre os interlocutores e pela aquisição e desenvolvimento da linguagem oral. Esses conteúdos fazem parte do complexo processo terapêutico proposto aos deficientes auditivos, principalmente os indivíduos portadores do ENA.

Pode-se concluir, então, que a intervenção fonoaudiológica proporcionou melhora nas habilidades pragmáticas de comunicação.

\begin{abstract}
Human communication depends mostly on the conversion of ideas into language, involving the interaction among all its components - phonological, semantic, syntactic and pragmatic. Pragmatics studies the relationship between the social meaning of language and its semantic content, expressed by the communicative act itself. Auditory neuropathy spectrum disorder generates a dyssynchrony in nerve conduction, contributing to an impairment in speech perception. In hearing impaired children the language acquisition and development process can be stimulated with intervention. The aim of this study was to present a longitudinal follow-up of the use of pragmatic communication abilities by a child with auditory neuropathy spectrum disorder. The child received speech-language pathology therapy during three years in the Educational Audiology area. Video recordings of spontaneous conversation were made in the beginning of each year. These recordings were transcribed and analyzed according to the verbal communicative abilities protocol. In the initial recording, the most frequent ability presented by the child was the direct response; however these were extended to more complex responses during the intervention. In the last recording the child proposes new topics of discourse, produce narratives and arguments. The emergence of more sophisticated communication skills is justified by the language development, which benefits from language therapy with hearing impaired children. This suggests that, for the case study described, speech-language pathology therapy contributed to the improvement of pragmatic communication abilities.
\end{abstract}

Keywords: Auditory neuropathy; Speech; Language; Hearing loss; Communication; Rehabilitation of speech and language disorders; Rehabilitation of hearing impaired; Child

\title{
REFERÊNCIAS
}

1. Lima FT, Araújo CB, Souza EC, Chiari BM. Alterações fonoaudiológicas presentes em um caso de síndrome de Goldenhar. Rev Soc Bras Fonoaudiol. 2007;12(2):141-5.

2. Befi-Lopes DM, Puglisi ML, Rodrigues A, Giusti E, Gândara JP, Araújo K. Perfil comunicativo de crianças com alterações específicas no desenvolvimento da linguagem: caracterização longitudinal das habilidades pragmáticas. Rev Soc Bras Fonoaudiol. 2007;12(4):265-73.

3. Most T, Shina-August E, Meilijson S. Pragmatic abilities of children with hearing loss using cochlear implants or hearing aids compared to hearing children. J Deaf Stud Deaf Educ. 2010;15(4):422-37.

4. Nicholas JG, Geers AE. Effects of early auditory experience on the spoken language of deaf children at 3 years of age. Ear Hear. 2006;27(3):286-98.

5. Guidelines for identification and management of infants and young children with auditory neuropathy spectrum disorder - NHS 2008 [ cited 2010 Jul 26] Available from: http://www.thechildrenshospital.org/pdf/ Guidelines\%20for\%20Auditory\%20Neuropathy\%20-\%20BDCCH.pdf.

6. Huang BY, Roche JP, Buchman CA, Castillo M. Brain stem and inner ear abnormalities in children with auditory neuropathy spectrum disorder and cochlear nerve deficiency. AJNR Am J Neuroradiol. 2010;31(10):1972-9.

7. Anastasio ART, Alvarenga KF, Costa Filho OA. Eletrococleografia extratimpânica na neuropatia/dessincronia auditiva. Rev Bras Otorrinolaringol. 2008;74(1):132-6.
8. Rodrigues GRI, Fichino SN, Lewis DR. Presença de microfonismo coclear no peate-clique: diagnóstico diferencial entre espectro da neuropatia auditiva e perdas auditivas cocleares descendentes em crianças. Rev CEFAC. 2010;12(6):1077-83.

9. Yalçınkaya F, Muluk NB, Ata A, Keith RW. Random Gap Detection Test and Random Gap Detection Test-Expanded results in children with auditory neuropathy. Int J Pediatr Otorhinolaryngol. 2009;73(11):155863.

10. Moeller MP, Tomblin JB, Yoshinaga-Itano C, Connor CM, Jerger S. Current state of knowledge: language and literacy of children with hearing impairment. Ear Hear. 2007;28(6):740-53.

11. Rance G, Barker EJ. Speech and language outcomes in children with auditory neuropathy/dys-synchrony managed with either cochlear implants or hearing aids. Int J Audiol. 2009;48(6):313-20.

12. Lopes SA. Habilidades comunicativas verbais em autismo de alto funcionamento e Síndrome de Asperger [dissertação]. São Carlos: Centro de Educação e Ciências Humanas da Universidade Federal de São Carlos; 2000.

13. Prado AC. Principais características da produção vocal do deficiente auditivo. Rev CEFAC. 2007;9(3):404-10. 
Anexo 1. Descrição habilidades comunicativas verbais ${ }^{(12)}$

\section{Habilidades dialógicas (HD)}

Início de turno (IT). Habilidade em iniciar um diálogo, quando ainda nenhum assunto foi abordado, com exceção dos cumprimentos sociais convencionais. Ex: um interlocutor diz ao outro "Vamos brincar de bola?".

Manutenção de diálogo (MD). Habilidade em manter um tópico de conversação proposto pelo interlocutor (atendo-se ao contexto) ou de tentar focalizar a atenção do interlocutor em determinado tópico já iniciado (incluem-se aqui recursos como a repetição de parte de um ununciado para sua posterior continuidade, evitando a quebra do diálogo) . Ex: quando um interlocutor diz "Vamos brincar de bola?" e o outro responde "De bola? Tudo bem, mas só se for de futebol!".

Inserção de novos tópicos no diálogo (NT). Habilidade em sugerir, dentro de um diálogo, novos tópicos de conversação. Ex: quando estão jogando futebol, um interlocutor diz ao outro "Quem será que vai ganhar o Campeonato Brasileiro?".

Organização dialógica sequencial (OS). Habilidade em respeitar as convenções de organização sequencial das conversações, para preenchimento de turno dialógico, através de recursos como:

1. Comentários $(\mathrm{CM})$ - emissões utilizadas para identificar ou descrever objetos, pessoas ou ações sem outra função que não a de partilhar a informação com o interlocutor. Tais emisões podem se constituir de enunciados verbais completos ou vocalizações (incluindo onomatopeias ou músicas). Ex: um interlocutor fala "Este carro é um fusca" e imita o som do carro.

2. Respostas diretas (RD) - quando, após uma indagação direta ou indiretamente formulada pelo interlocutor, há a presença de uma resposta verbal contextual ou de atos motores (acompanhados de verbalizações). Ex: um interlocutor solicita "Você pode pegar a caneta para mim?" e o outro fala "'Tá aqui sua caneta!", ao mesmo tempo que a pega e devolve ao outro.

3. Imitação (I) - quando, para preencher um turno do diálogo, há apenas a repetição da fala do interlocutor ou de alguma outra emissão relacionada ao assunto e evocada pelo diálogo.Ex: um interlocutor fala "Qual sua novela preferida?" e o outro responde "Novela...O rei do Gado, da Globo e você - tudo a ver".

4. Feedback ao interlocutor $(\mathrm{FI})$ - composto de enunciados ou expressões que indicam apenas atenção à fala do outro, tendo o intuito de reforço ou correção. Ex: quando um interlocutor está falando e o outro exclama "Hã, hã" ou "Certo, certo..." ou "Fala mais alto!".

Reparação de falhas (RF). Quando há a repetição integral ou em parte de uma emissão, para correção de algum erro de pronúncia ou formulação em si ou no outro. Ex: um interlocutor está falando "Ontem, eu fui ao paque, quer dizer, ao parque".

Variação de papeis (VP). Quando há utilização de formas verbais lúdicas que indiquem a emissão de um outro falante não presente, real ou fictício. Ex: ao contar uma história que aconteceu em casa, um interlocutor diz "Daí, minha mãe falou: - Menino, como você está sujo!" ou, ao brincar de fantoche, um dos interlocutores fala no lugar do boneco.

Rotina social (RS). Uso de emissões estereotipadas e socialmente adotadas no início ou final das interações sociais, tais como cumprimentos, agradecimentos e outras emissões de função fática. Ex: "Oi, tudo bem?" ou "Tchau, até amanhã!".

Expressão de sentimentos (ES). Emissões cuja função é a de expressar sentimentos como protesto, surpresa, agrado, desagrado ou qualquer outra reação emocional. Ex: um interlocutor diz, ao final de um jogo "Adorei brincar com este jogo! É muito legal!"

\section{Habilidades de regulação (HR)}

Auto-regulatória (AR). Emissões utilizadas para controlar verbal- mente sua própria ação. As emissões precedem imediatamente ou acompanham o comportamento motor referido. Ex: o interlocutor exclama "Calma!" enquanto tenta tirar o sapato (e não está conseguindo).

Direcionamento de atenção (DAT). Qualquer emissão realizada no sentido de chamar a atenção do interlocutor par si mesmo, uma ação ou objeto determinado. Ex: um interlocutor diz ao outro "Olha aquilo, que bonito!".

Direcionamento de ação (DAO). Qualquer emissão realizada no sentido de controlar, solicitar ou acompanhar uma ação direta do interlocutor. Ex: um interlocutor diz ao outro "Termina este desenho mais rápido, termina!".

Solicitação de objeto (SO). Emissões utilizadas para solicitar um objeto concreto ao outro. Ex: "Me passa aquele brinquedo ali!"

Solicitação de informação (SI). Emissões utilizadas no sentido de solicitar uma informação do interlocutor. Podem ser compostas de expressões interrogativas diretas ou indiretas. Ex: "Você tem namorado?".

Consentimento (CS). Emissões que solicitam o consentimento do outro para realização de uma ação. Ex: "Posso pegar aquele caderno depois de guardar o livro?"

\section{Habilidades narrativas/discursivas (HND)}

Relato de histórias ou acontecimento $(\mathrm{RH})$. Habilidade de relatar um fato ou história de forma coerente, através de emissões espontâneas, com ou sem o auxílio do interlocutor. Ex: um interlocutor começa contar uma história, a partir de figuras que vê "Era uma vez uma menina que vivia triste..."

Reprodução de histórias (RPH). Habilidade em reproduzir integral ou parcialmente um fato ou história relatado por outrem ou lida, com ou sem auxílio do interlocutor. Ex: ao se acabar de contar uma história, como a Branca de Neve, o outro imediata ou posteriormente q reproduz de forma correta "Era uma vez uma moça bonita, branquinha, branquinha como a neve...".

Interpretação de histórias (IH). Habilidade de tirar conclusões e emitir opiniões sobre fatos ou histórias e de compreendê-las. Ex: depois de contar uma história, pergunta-se "Por que será que a bruxa queria matar a Branca de Neve?" e o outro responde "Porque a bruxa era feia e má e tinha muita inveja da moça bonita e boazinha".

Argumentação (ARG). Habilidade em utilizar emissões próprias para convencer o outro, utilizando argumentos verbais e convincentes. Ex: um interlocutor diz "Agora, vamos ter que guardar os brinquedos e ir embora." e o outro responde "Mas é cedo ainda e meu ônibus vai demorar para passar, além disso você prometeu deixar eu ver o livro novo".

\section{Habilidades verbais não-interativas (HNI)}

Uso da linguagem para estabelecimento da própria identidade (LPI). Quando o indivíduo refere-se a si mesmo em suas emissões verbais. Ex: "Daí, eu fiquei muito bravo e disse - Não bate mais em mim, que eu sou forte!".

Jogo simbólico (JS). Uso da linguagem para estabelecimento de relações de representação direta ou indireta de objetos, ações ou pessoas com determinadas expressões verbais. Ex: um interlocutor diz, ao contar a história da Chapeuzinho Vermelho - "Os meus olhos são grandes, mas é para te ver melhor!", fazendo a entonação de fala do lobo.

Metalinguagem (ML). Quando o indivíduo se utiliza da fala para se referir a própria fala ou linguagem. Ex: "Eu acho que falar serve para as pessoas ficarem só assim, mexendo a boca. Eu já pensava mesmo, antes de só falar" - resposta de um interlocutor ao outro, quando indagado por que as pessoas falavam. 